\title{
MiR-495 Promotes Senescence of Mesenchymal Stem Cells by Targeting Bmi-1
}

\author{
Xiujun Lia Yuxian Song ${ }^{\mathrm{b}}$ Dan Liu ${ }^{\mathrm{a}}$ Jiaojiao Zhao ${ }^{\mathrm{b}}$ Jingjing $\mathrm{Xu}^{\mathrm{b}}$ Jing Ren $^{\mathrm{b}}$ \\ Yali Hua,c Zhiqun Wanga Yayi Hou ${ }^{\mathrm{b}}$ Guangfeng Zhao
}

aDepartment of Obstetrics and Gynecology, The Affiliated Drum Tower Hospital of Nanjing University

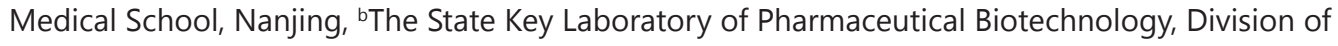
Immunology, Medical School, Nanjing University, Nanjing, cJiangsu Key Laboratory of Molecular Medicine, Nanjing, China

\section{Key Words}

MSC $・$ Preeclampsia $・$ MiR-495 $\cdot$ Senescence $\cdot$ Bmi-1

\begin{abstract}
Background/Aims: Mesenchymal stem cells (MSCs) play an important role in regulating angiogenesis and immune balance. Abnormal proliferation and function of MSCs were reported at maternal fetal interface in patients with pre-eclampsia (PE). Micro-RNA-495 was known to be upregulated in the MSCs derived from patients with PE. However, it is not clear whether the up-regulated miR-495 is related to the pathogenesis of PE. Methods: We analyzed the expression of miR-495 in MSCs and umbilical cords derived from healthy pregnancies (NC) and $\mathrm{PE}$, then we upregulated or downregulated the expression of miR-495 in MSCs derived from NC and tested the proliferation, apoptosis, migration, invasion, tube formation and senescence. Results: In the current study, we found that the expression of miR495 was significantly increased in both umbilical cord tissues and MSCs in patients with severe PE. Overexpressing miR-495 arrested cell cycle in S phase and promoted cell apoptosis. The supernatants from miR-495-overexpressed-MSCs inhibited the migration of MSCs and HTR8/SVneo, invasion of HTR-8/SVneo and tube formation of HUVEC, while si-miR-495 had the opposite effects. Furthermore, we analyzed the senescence related $\beta$-galactosidase activity and CD146 and found that miR-495 induced the senescence of MSCs. Molecular mechanism studies confirmed that Bmi-1 mediated these effects of miR-495 on MSCs. Conclusion: Taken together, our data demonstrated that miR-495 induced senescence of MSCs may be involved in the pathogenesis of PE.
\end{abstract}

\section{Introduction}

Pre-eclampsia (PE) is a disease of pregnancy characterized by hypertension and proteinuria, developing after 20 weeks of gestation. It has been estimated that $5 \%-7 \%$ of pregnancies worldwide are complicated by this disorder, resulting in a very large disease

Guangfeng Zhao, Ph.D., Yayi Hou and Zhiqun Wang

KARGER
Department of Obstetrics and Gynecology, The Affiliated Drum Tower Hospital of Nanjing University Medical School, 321 Zhongshan Rd., Nanjing 210008, (China); The State Key Laboratory of Pharmaceutical Biotechnology, Division of Immunology, Medical School, Nanjing University, Nanjing, (China)

E-Mail zgfwindman@gmail.com / yayihou@nju.edu.cn / 13815885457@163.com 
burden [1]. Although much research has been devoted toward this topic, its pathogenesis is still incompletely understood yet [2-5].

Maternal-fetal interface is an important source of mesenchymal stem cells (MSCs) [6]. MSCs are a set of cells capable of self-renewal, expansion and multi-lineage differentiation. Previous studies have found that both umbilical cord and decidua derived MSCs were abnormal in PE, showing impaired proliferation, angiogenesis and immunoregulation [7, 8]. Interestingly, when we used MSCs to treat Th-1-induced PE-like mice, the PE symptoms were ameliorated [9]. Fu also reported that human umbilical cord-derived MSCs could release the PE-like symptoms of endotoxin-induced rat model through reducing the levels of pro-inflammatory TNF $\alpha$ and IL-1 $\beta$ and increasing the levels of anti-inflammatory IL-10 [10]. Additionally, in vitro experiments showed that MSCs from PE inhibited angiogenesis through reducing VEGF $[7,11,12]$ and modulate the immune response through keeping the balance of pro-inflammatory and anti-inflammatory factors [11,13-15]. These results indicate that maternal-fetal interface derived MSCs play an important role in the pathogenesis of PE. However, the reasons leading to the abnormal growth and function of MSCs are still unclear.

Aberrant senescence in the placenta may contribute to PE [16]. It was reported that early onset preeclampsia is associated with placental aging [17]. Trophoblasts and in cord blood cells from pregnancies complicated with PE showed increased senescence [18]. It is unknown whether MSCs are senescent in PE. However, it was reported that human umbilical cord-derived MSCs have anti- senescence ability $[19,20]$. Additionally, in the senescent state, MSCs show impaired proliferation and differentiation capacity [21, 22]. Therefore, we speculated that aberrant senescence may contribute to abnormal growth and function of MSCs in PE.

MicroRNAs (miRNAs) play important roles in the regulation of cellular senescence [23, 24] and the pathogenesis of PE [25]. MiR-495 was reported as an anti-tumor miRNA which could inhibit cell migration, invasion and proliferation, thus to play negative roles in the carcinogenesis [26-29]. What's more, miR-495 was reported to suppress breast cancer cell proliferation and tumorigenicity via G1-S arrest through targeting the 3'UTR of Bmi-1 [30]. In our previous study, we reported that miR-495 was highly expressed in MSCs [31]. But the role of miR-495 plays in senescence regulation hasn't been reported yet.

In the current study, we aimed to investigate the possible roles of miR-495 in the pathophysiology of PE and its functions in MSCs. We tested the expression of miR-495 in umbilical cords and MSCs derived from healthy donors and PE patients and we found that miR-495 was highly expressed in PE. Furthermore, we found that miR-495 inhibited the proliferation, migration and angiogenesis of MSCs and promoted cell apoptosis and aging through targeting Bmi-1.

\section{Materials and Methods}

Umbilical cord collection

PE was defined as gestational hypertension (systolic pressure $>140 \mathrm{mmHg}$ or diastolic blood pressure $>90 \mathrm{mmHg}$ on two or more occasions after gestational week 20) with proteinuria $(>0.3 \mathrm{~g} / \mathrm{day})$. Umbilical cord tissues were obtained from healthy pregnancies (NC) $(n=24)$ and PE pregnancies $(n=24)$ who underwent caesarean section in Drum Tower Hospital from Sep 2015 to Apr 2016. This study had got approved by the Nanjing Drum Tower Hospital Ethics-Committee and all healthy controls and patients had written consent. Multiple gestations and the presence of maternal chronic hypertension, the HELLP syndrome, chronic nephritis, gestational diabetes mellitus, hepatic disease, in vitro fertilization and embryo transfer (IVF-ET) or other infectious and neoplastic disease and fetal congenital defect were excluded. The relevant clinical characteristics of the patients are presented in Table 1 and 2.

MSCs isolation and culture

MSCs were isolated from umbilical cord tissues within 4 hours as we reported previously in our laboratory. MSCs were obtained from healthy pregnancies (NC) $(n=6)$ and PE pregnancies $(n=8)$. Umbilical 
Table 1. The clinical characteristics of umbilical cords. Abbreviations: PE, preeclampsia; NS, not significant

\begin{tabular}{lccc}
\hline Parameter & PE $(\mathrm{n}=24)$ & Control $(\mathrm{n}=24)$ & P value \\
\hline Age, years & $29.5 \pm 0.9$ & $28.9 \pm 0.5$ & NS \\
Primiparae(n) & $14(58.3 \%)$ & $15(62.5 \%)$ & NS \\
Gestational age at delivery, weeks & $37.8 \pm 0.1$ & $38.5 \pm 0.2$ & NS \\
Body mass index $\left(\mathrm{kg} / \mathrm{m}^{2}\right)$ & $29.3 \pm 0.9$ & $27.8 \pm 3.1$ & NS \\
Systolic blood pressure (mmHg) & $158.7 \pm 9.1$ & $110.2 \pm 4.7$ & $<0.05$ \\
Diastolic blood pressure (mmHg) & $117.5 \pm 3.4$ & $77.4 \pm 5.2$ & $<0.05$ \\
Proteinuria (mg/24h) & $1702.6 \pm 40.25$ & 0 & $<0.05$ \\
Blood urea nitrogen (mmol/l) & $3.6 \pm 0.7$ & $3.4 \pm 0.5$ & NS \\
Alanine aminotransferase (units/l) & $29.7 \pm 3.9$ & $30.0 \pm 8.3$ & NS \\
Placenta weight (g) & $579.4 \pm 40.2$ & $575.2 \pm 37.8$ & NS \\
Platelets (n) & $(179.1 \pm 40.3) \times 10^{9}$ & $(180.4 \pm 30.9) \times 10^{9}$ & NS \\
Birth weight (g) & $2907.8 \pm 206.0$ & $3182.2 \pm 103.2$ & NS \\
\hline
\end{tabular}

Table 2. The clinical characteristics of MSCs. Abbreviations: PE, preeclampsia; NS, not significant

\begin{tabular}{llll}
\hline Parameter & PE $(\mathrm{n}=8)$ & Control $(\mathrm{n}=6)$ & P value \\
\hline Age, years & $29.6 \pm 0.2$ & $28.7 \pm 0.9$ & NS \\
Primiparae(n) & $4(50.0 \%)$ & $4(66.6 \%)$ & NS \\
Gestational age at delivery, weeks & $37.7 \pm 0.8$ & $38.4 \pm 0.7$ & NS \\
Body mass index $\left(\mathrm{kg} / \mathrm{m}^{2}\right)$ & $29.1 \pm 0.3$ & $28.2 \pm 2.8$ & NS \\
Systolic blood pressure $(\mathrm{mmHg})$ & $166.8 \pm 10.6$ & $105.7 \pm 6.8$ & $<0.05$ \\
Diastolic blood pressure $(\mathrm{mmHg})$ & $114.9 \pm 4.2$ & $78.2 \pm 8.4$ & $<0.05$ \\
Proteinuria (mg/24h) & $1802.6 \pm 39.2$ & 0 & $<0.05$ \\
Blood urea nitrogen (mmol/l) & $4.1 \pm 0.2$ & $3.8 \pm 0.2$ & NS \\
Alanine aminotransferase (units/l) & $31.5 \pm 3.2$ & $30.8 \pm 6.6$ & NS \\
Placenta weight (g) & $604.2 \pm 28.9$ & $592.3 \pm 32.9$ & NS \\
Platelets (n) & $(167.3 \pm 39.5) \times 10^{9}(170.9 \pm 29.6) \times 10^{9}$ & NS \\
Birth weight (g) & $2794.2 \pm 328.5$ & $2867.3 \pm 97.4$ & NS \\
\hline
\end{tabular}

cord tissues were washed with PBS several times until no blood can be seen and the two umbilical arteries and the umbilical vein were dissected before tearing up and cutting the tissues to pieces in PBS. Then the tissues were incubated in an enzyme cocktail for $3 \mathrm{~h}$ with gentle agitation at $37^{\circ} \mathrm{C}$. The digestion mixture was washed with PBS and then washed with Dulbecco's modified Eagle's medium/F12 (DF-12, Gibco, Grand Island, NY, USA). Then the mixture was suspended in fresh DF12 supplemented with $20 \%$ fetal bovine serum (FBS) containing $100 \mathrm{IU} / \mathrm{mL}$ antibiotics and incubated at $37^{\circ} \mathrm{C}$ in a $5 \% \mathrm{CO}_{2}$ saturating humidified atmosphere. After two days of incubation, remove the small resides not attached and add fresh complete medium gently. The medium was replaced two times every week. The culture continued until the cells cover the whole plate then cells were detached using $0.25 \%$ trypsin/EDTA to transfer to a new culture plate.

The specific phenotypic surface antigens of MSCs were characterized by flow cytometry (BD, FACS Calibur) assay after the $2 \mathrm{nd}$ to 4 th cell passages. As was reported before, the adherent, fibroblast-like cells were presented as CD105+, CD73+, CD90+, CD44+, CD29+, HLA-DR-, CD31-, CD14-, CD19-, CD106-, CD11band CD45-[32]. We also tested the expression of CD146, which was reported to be a marker of MSCs [33, 34], after transfecting si-NC, si-495, mic-NC, miR-495. 


\section{Cellular Physiology Cell Physiol Biochem 2017;42:780-796

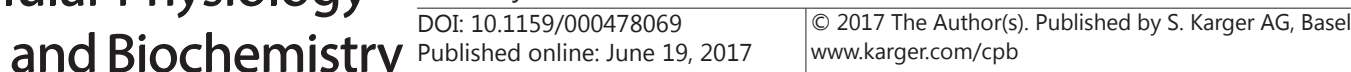

Li et al.: MiR-495 Contributes to the Pathogenesis of PE

Transient transfection

Overexpression of miR-495 in MSCs was achieved by transfecting cells with miR-495 mimic (mic-495) and miR-495 mimic negative control (mic-NC) (RIBO BIO, Guangzhou, China) using lipofectimine-2000 reagent (Invitrogen) until MSCs reached 30-50\% confluence and represented a logarithmic growth. A sequence of small interfering RNAs for miR-495 (si-495) and interfering negative control (si-NC) were ordered from RIBO BIO. After transfection for 48 hours, cells and the supernatants were harvested for the following experiments.

\section{Cell Line and culture}

HTR-8/SVneo cells and human umbilical vein endothelial cells (HUVEC) were cultured in RPMI-1640 (Gibco), supplemented with $10 \% \mathrm{FBS}$ and $100 \mathrm{IU} / \mathrm{mL}$ antibiotics, at $37^{\circ} \mathrm{C}$ in a humidified atmosphere with $5 \% \mathrm{CO}_{2}$.

Cell proliferation, cell cycle and apoptosis assays

A CCK-8 kit (DojinDo) was used to detect the effect of miR-495 on the viability of MSCs. A cell counting kit was used to achieve a qualitative index of cell viability after transfection in our experiments. After transfection for 48 hours, CCK- 8 was separately added to each well and incubation for another 3 hours. An OD absorbance at $450 \mathrm{~nm}$ was measured by a multi-detection micro plate reader (Bio-Tek). For the cell cycle experiments, the treated cells were harvested, washed once with PBS and fixed in 70\% ethanol overnight. Staining of the DNA content was performed with $50 \mathrm{mg} / \mathrm{ml} \mathrm{PI}, 1 \mathrm{mg} / \mathrm{ml}$ RNase A and $0.2 \%$ Triton-X100 for 30 min. Analysis was performed with MFLT32 software. For apoptosis assay, 48 hours after transfection, cells and their supernatants were harvested, centrifuged and washed with PBS. Then cells were resuspended with 200ul PBS, stained with $5 \mathrm{ul}$ Annexin V and incubated for 15 minutes in the dark. Then PI was added (final concentration was $1 \mu \mathrm{g} / \mathrm{ml}$ ) and incubated for another 5 minutes in the dark. Cells were detected by FACs Calibur. Analysis was performed with FlowJo-V10 (BD Biosciences).

\section{Quantitative RT-PCR analysis}

Total RNA, including miRNA, was extracted using Trizol reagent (Invitrogen) according to the manufacturer's instructions. The concentration of RNA was measured using a SmartSpecTM Plus spectrophotometer (Bio- Rad, Hercules, CA, USA). $1 \mu \mathrm{g}$ total RNA was reverse-transcribed into cDNA using reverse transcriptase, reverse transcriptase buffer, dNTPs, RNase inhibitor and OligodT in the Thermoscript (TaKaRa). The cDNA obtained was used for real-time quantitative PCR (q-PCR) by using an Applied BioSystems step-one detection system with SYBR green dye (Invitrogen). For relative quantification of the mRNA expression, the expression of GAPDH was used as an endogenous control. The method to quantify mature miRNAs was performed by stem-loop RT-PCR. $1 \mu \mathrm{g}$ RNA and primers were put at $65^{\circ} \mathrm{C}$ for 5 minutes to form highly target-specific stem-loop structure, then reverse transcriptase, RNase inhibitor, dNTPs and $5 \mathrm{x}$ buffers were added for reverse transcription. The whole procedure was performed on ice. Besides, the miRNAs amplification was performed by using an Applied Bio-Systems step-one detection system with SYBR green dye (Invitrogen). For relative quantification, the expression of U6 snRNA (Applied Biosystems) was used as an endogenous control. All experiments were performed in triplicate $(n=3)$. Relative expression was performed using the DDCt method.

\section{Western blot analysis}

Whole cell lysate for western blotting were extracted with lysis buffer containing $50 \mathrm{mM}$ Tris (pH 8), HEPES (pH 7.5), $150 \mathrm{mM} \mathrm{NaCl}, 1.5 \mathrm{mM} \mathrm{MgCl} 2,1 \mathrm{mM}$ EDTA, $0.1 \%$ Triton X-100, 0.25\% sodium deoxycholate and protease inhibitor (Roche). Lysates $(50 \mu \mathrm{g})$ were resolved by 12\% SDS/PAGE (Bio-Rad), and gels were transferred to poly (vinylidene difluoride) membranes (Roche). Membranes were blocked using 5\% Bovine Serum Albumin (BSA) for 2 hours at room temperature, and subsequently incubated overnight at $4^{\circ} \mathrm{C}$ with diluted primary antibodies against Bmi-1 and GAPDH (1:1000 dilution) (Millipore, Billerica, MA). Signals were detected using the appropriate horseradish peroxidase-conjugated secondary antibody (Cell Signaling Technology). The blots were visualized using an enhanced Immobilon Western chemiluminescent horseradish peroxidase (HRP) substrate (Millipore, Billerica, MA), according to the manufacturer's instructions.

\section{KARGER}




\section{Cellular Physiology Cell Physiol Biochem 2017;42:780-796 \begin{tabular}{l|l} 
and Biochemistry Publis.1159/000478069 & $\begin{array}{l}\text { (c) 2017 The Author(s). Published by S. Karger AG, Basel } \\
\text { www.karger.com/cpb }\end{array}$
\end{tabular}}

Li et al.: MiR-495 Contributes to the Pathogenesis of PE

HTR-8/SVneo invasion assay

The transwell invasion experiments were performed using transwell membrane filters ( $8 \mu \mathrm{m}$ size pore, Millipore). Before the experiments, $80 \mu \mathrm{l}$ Matrigel (BD) was added to the upper chamber and incubated at $37^{\circ} \mathrm{C}$ till the Matrigel coagulated. Then supernatants were added to the lower chamber, and $100 \mu \mathrm{l}$ HTR-8/ SVneo cells were seeded in the upper chamber at a density of $2 \times 10^{5} / \mathrm{ml}$. After 24 hours' incubation, nonmigrating cells on the upper surface of the membrane were removed with a cotton swab. The migrated cells on the lower surface of the membranes were fixed with 4\% PFA for 30 min at room temperature, stained with crystal violet solution for $20 \mathrm{~min}$. After washed with distilled water, ten randomly chosen fields were imaged and quantified by blind counting of the migrated cells of ten fields per chamber. All experiments were performed in triplicate $(n=3)$.

\section{MSC and HTR-8/SVneo migration assay}

After 48 hours' transfection, MSCs were scratched with $1 \mathrm{ml}$ pipett and washed with PBS to remove the cell debris. Then MSCs were incubated in fresh medium containing 10\% FBS. HTR-8/SVneo cells were also scratched as described above and incubated in fresh RPMI-1640 containing 10\% FBS and 50\% MSC supernatant. Pictures were taken under a microscope at $40 \times$ magnification and the results were analyzed using ImageJ Launcher.

\section{HUVEC capillary tube and network formation assay on Matrigel}

Matrigel (BD Biosciences, San Jose, CA, USA) $(100 \mu \mathrm{L})$ was added to 48 -well plates and incubated for 40 minutes for gelling. HUVEC $\left(8 \times 10^{3}\right)$ were added to the pre-solidified Matrigel together with equal volume of conditioned MSC supernatants. The cells started the process of forming capillary tubes and networks once seeded on Matrigel. Incubation for 8 hours revealed the most pronounced difference between treated groups in terms of capillary tube and network morphology. Tube-like structures were defined as endothelial cord formations that were connected at both ends, and the mean tube length in five random fields per well was quantified. These results were analyzed using ImageJ Launcher.

\section{$\beta$-galactosidase activity assay}

Senescent cells were assessed by staining for $\beta$-galactosidase activity using MSCs at passage 3.48 hours after transfection with mic-NC, mic-495, si-NC or si-495, $\beta$-galactosidase activity of MSCs was tested using a Senescence $\beta$-galactosidase Staining Kit (Beyotime Biotechnology) according to the manufacturers' instructions. Briefly, MSCs were seeded in 12-well plates and after the corresponding treatments. And MSCs were washed twice with PBS and fixed with Fixative Solution for $15 \mathrm{~min}$ at room temperature. Then, the MSCs were stained with $1 \mathrm{ml}$ complete $\beta$-galactosidase staining solution per well overnight at $37^{\circ} \mathrm{C}$. The complete $\beta$-galactosidase staining solution contained Solution A, Solution B, Staining Solution C and X-gal solution (final concentration of $1 \mathrm{mg} / \mathrm{ml}$ ). After cultured at $37^{\circ} \mathrm{C}$ without $\mathrm{CO}_{2}$, the cells were washed twice with PBS and pictures were taken under a microscope at $100 \times$ magnification. Ten randomly chosen fields were imaged and quantified by blind counting of the positive cells of ten fields per chamber. All experiments were performed in triplicate $(n=3)$.

\section{Dual-luciferase assays}

For luciferase assays, MSCs were pre-seeded into 12-well plates 1 day before transfection. Then the firefly luciferase plasmid of Bmi-1 3' untranslated region (UTR) and mutated plasmid of Bmi-1 3' UTR (mut), constructed by GENEray, as well as si-495, mic-495 or negative control, were co-transfected into each well. 48 hours post-transfection, cell lysates were prepared using reporter lysis buffer (Promega). Luciferase activity was analyzed using a luciferase assay kit (Promega) with GloMaxTM96 Microplate Luminometer w/Dual Injectors (E6521) according to the manufacturers' instructions.

\section{Statistical analysis}

All experiments were performed at least three times and data are expressed as mean \pm S.E.M. Graphpad prism version 5.01 was used to perform graphics and the two-tailed student's t-test was used to compare statistical significance. $P<0.05$ was set as a statistical significance. 


\section{Results}

MiR-495 was highly expressed in umbilical cords and MSCs derived from patients with PE Our previous study showed that miR-495 was highly expressed in MSCs derived from decidua tissues of PE patients [31]. In the current study, we tested the expression of miR-495 in umbilical cord tissues and MSCs obtained from umbilical cords. The results showed that miR-495 was highly expressed both in umbilical cords (Fig. 1A) and MSCs (Fig. 1B) derived from PE compared with healthy donors (NC).

\section{MiR-495 could not change the phenotype of MSCs}

As miR-495 was highly expressed in MSCs derived from PE compared with NC, we wondered whether miR-495 was involved in the pathology of PE. MiR-495 mimic (mic-495), miR-495 mimic negative control (mic-NC), interfering RNAs from miR-495 (si-495) and interfering negative control (si-NC) were transfected into MSCs using lipofectimine-2000 reagent. After $48 \mathrm{~h}$, cells and supernatant were collected and tested. The mic-495 could overexpress miR-495 (Fig. 2A) and the miR-495 interfering RNA could downregulate miR495 significantly (Fig. 2B).

To test whether miR-495 changed the phenotype of MSCs, we analyzed the expression of CD90, CD44, CD105, CD73, CD29, CD31, CD45, HLA-DR, CD14, CD19, CD106 and CD11b after transfection with miR-495 mimic and interfering RNA. The results showed that these antigens on the surface of MSCs were not changed significantly with the alteration of miR495 levels (Fig. 2C and 2D).

MiR-495 inhibits cell proliferation and induces apoptosis of MSCS

As miR-495 was highly expressed in PE, we wondered whether miR-495 could affect the growth of MSCs. We tested the cell viability after transfection with mic-495, mic-NC, si495 and si-NC into MSCs. The results of CCK-8 assay showed that overexpressing miR-495 inhibit cell viability of MSCs while si-495 promoted it (Fig. 3A). To figure out how miR-495 inhibits cell viability, we next analyzed the effects of miR-495 on cell cycle and apoptosis. The cell cycle analysis showed that overexpressed-miR-495 could arrest the cell in S phase $(11.56 \pm 0.2685$ mic-NC and $14.79 \pm 0.3883$ in miR-495, $p=0.0024)$ while decreased the G0/G1 phase (83.13 \pm 0.3500 mic-NC and $79.85 \pm 0.6454$ in miR-495, $p=0.0110$ ) compared with control (Fig. 3B and 3C). The apoptosis test showed that si-495 inhibited cell apoptosis $(8.230 \pm 0.2184$ in si-NC and $6.702 \pm 0.3641$ in si-495, $\mathrm{P}=0.0049)$ (Fig. 3D and 3E) while overexpressing miR-495 promoted cell apoptosis (8.022 \pm 0.3164 in mic-NC and $15.08 \pm$ 1.298 in miR-495, $\mathrm{P}=0.0004$ ) (Fig. $3 \mathrm{~F}$ and $3 \mathrm{G}$ ).

MiR-495 inhibits cell migration and invasion

Sufficient trophoblast invasion plays an important role in the formation of placenta and successful pregnancy and insufficient trophoblast invasion is regarded as one of the causes for PE. As described above, miR-495 could inhibit cell proliferation and promote cell apoptosis, so we wondered whether miR-495 had effects on the migration and invasion

Fig. 1. MiR-495 was highly-expressed both in umbilical cord tissues and MSCs in patients with severe PE. (A) The relative expression of miR-495 in the umbilical cord tissues from healthy donors (NC, $\mathrm{N}=$ 24) and PE patients $(\mathrm{N}=24)$. (B) The relative expression of miR-495 in MSCs derived from NC $(\mathrm{N}=6)$ and PE patients $(\mathrm{N}=8)$. Values are means \pm S.E.M. ${ }^{*} \mathrm{P}<$ 0.05 .

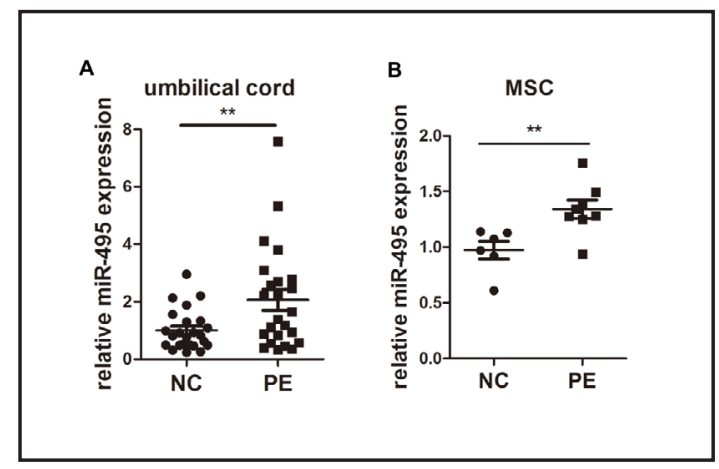




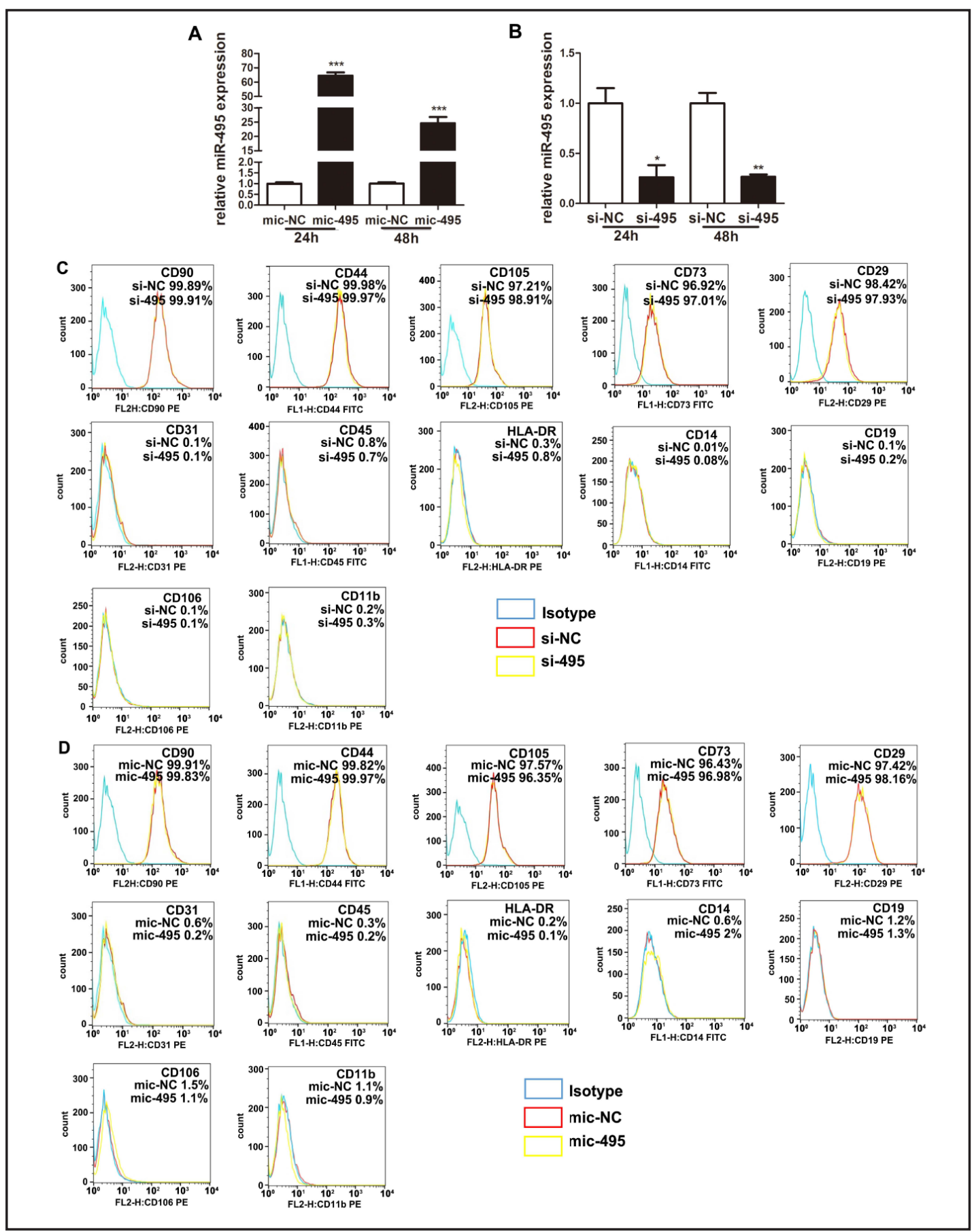

Fig. 2. MiR-495 could not change the phenotype of MSCs. After transfected the M-NC or M plasmid, the expression of MALAT1 was tested on mRNA level. (B) After transfected si-NC or si-M, the expression of MALAT1 was tested on mRNA level. (C and D) Expression of surface antigens, CD90, CD44, CD105, CD73, CD29, CD31, CD45, HLA-DR, CD14, CD19, CD106 and CD11b was detected using flow cytometry after transfected with si-NC, si-495, mic-NC or mic-495.

of MSCs and trophoblast cells. After changing the expression of miR-495, we tested the migration of MSCs and HTR-8/SVneo cells through scratching with a pipette. The results showed that miR-495-overexpressed MSCs migrated much more slowly (Fig. 4A and 4B) while miR-495-downregulated MSCs migrated faster (Fig. 4C and 4D) compared with 

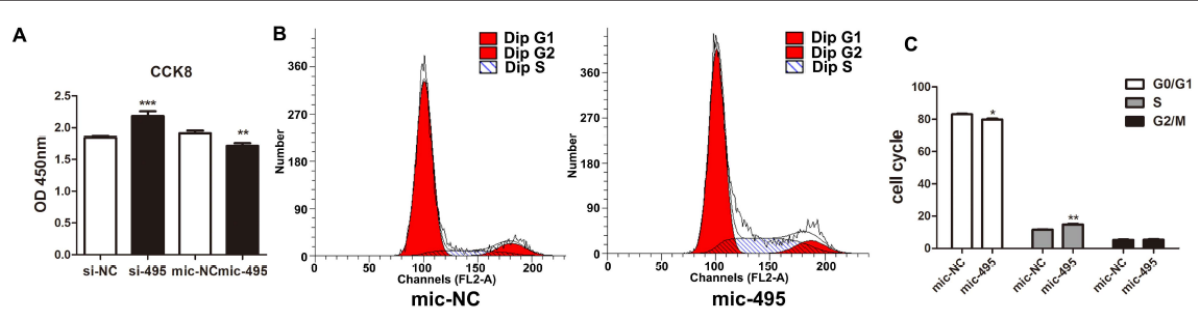

D
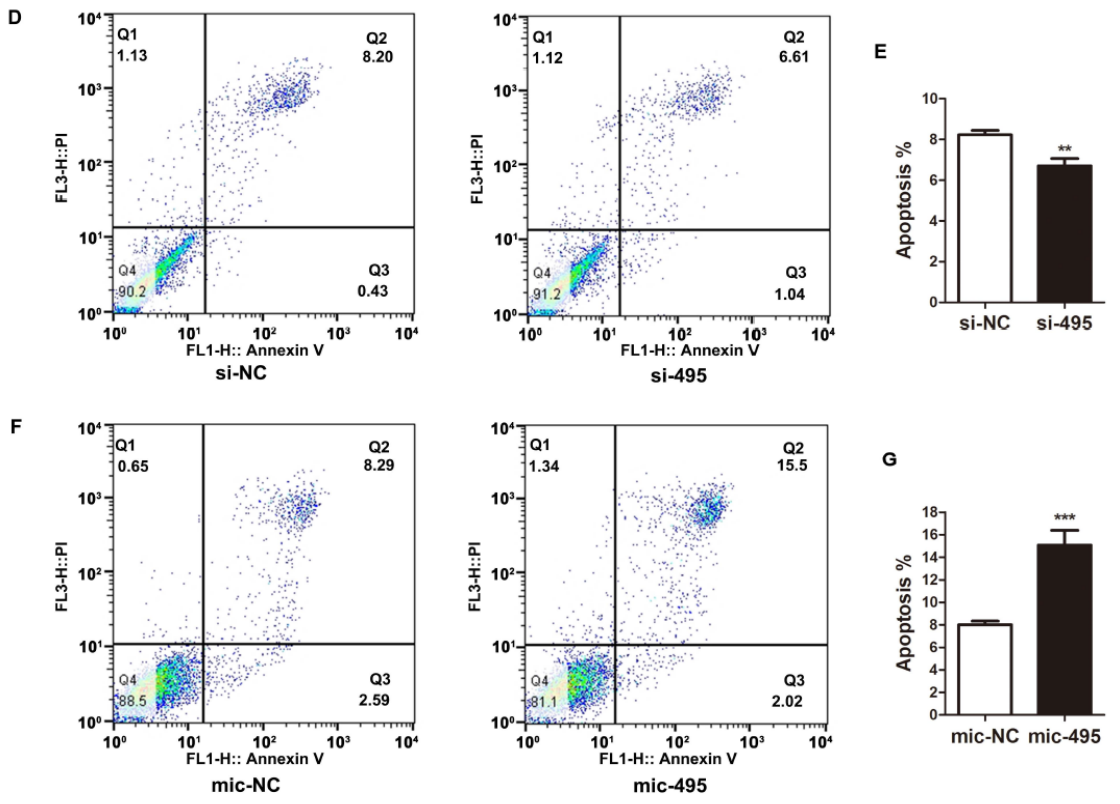

G

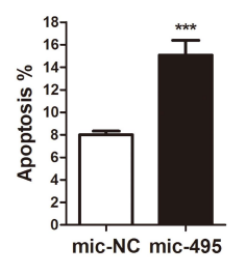

Fig. 3. MiR-495 inhibits cell proliferation and promotes cell apoptosis. (A) CCK8 test was performed after transfection of si-NC, si-495, mic-NC or mic-495 into MSCs. After transfection with mic-NC or mic-495 for 48 hours, cells were subsequently assayed for DNA content by flow cytometry. Images are shown on (B) for cell cycle distribution, and a statistical analysis shown on (C) for percentage of the cells in different phases of cell cycle. (D and E) Apoptosis of MSCs transfected with si-NC or si-495 for 48 hours was detected using flow cytometry. (F and G) Apoptosis of MSCs transfected with mic-NC or mic-495 for 48 hours was detected using flow cytometry. All results are from three independent experiments. Values are means \pm S.E.M. ${ }^{*} \mathrm{P}<$ $0.05,{ }^{* *} \mathrm{P}<0.01,{ }^{* * *} \mathrm{P}<0.001$.

control group both at 6 hours and 12 hours. The migration experiments of HTR-8/SVneo cells also showed that cells migrated slower when co-cultured with supernatants of miR495-overexpressed MSCs than cells co-cultured with supernatants of mic-NC-transfectedMSCs (Fig. 4E and 4F). Besides, HTR-8/SVneo cells migrated faster when co-cultured with supernatants of miR-495-downregulated-MSCs than cells co-cultured with supernatants of si-NC-transfected-MSCs (Fig. 4G and 4H).

The transwell experiments also showed that supernatants of miR-495 overexpressedMSCs decreased the invasion of HTR-8/SVneo cells (165.5 \pm 1.500 in mic-NC and $55.50 \pm$ 5.500 in miR-495, $\mathrm{P}=0.0027$ ) (Fig. $5 \mathrm{~A}$ and $5 \mathrm{~B}$ ) while si-495 increased the invasion of HTR8/SVneo compared with control groups $(168.5 \pm 7.500$ in si-NC and $251.5 \pm 8.500$ in si-495, $\mathrm{P}=0.0181$ ) (Fig. 5C and 5D).

\section{MiR-495 inhibits HUVEC capillary formation in vitro}

Insufficiency of angiogenesis is regarded one of the causes of PE. We wondered if miR-495 could affect the regulatory roles of MSCs in angiogenesis. We performed the tube formation analysis on Matrigel through co-culturing HUVEC with supernatants of MSCs after changing the expression of miR-495 in MSCs for 48 hours. After co-culturing for 8 hours, 
Fig. 4. Supernatants from miR-495-overexpressed-M S C s promote the migration of MSCs and invasion of HTR-8/ SVneo. (A) 48 hours after transfection of mic-NC or mic495 into MSCs, a scratch was performed using a $1 \mathrm{ml}$ pipette and pictures were taken using a microscope at $40 \times$ magnification after 0 hour, 6 hours and 12 hours. (B) The migration pictures of mic-NC and mic495 groups was analyzed. (C) 48 hours after transfection of si-NC or si-495 into MSCs, a scratch was performed using a 1 $\mathrm{ml}$ pipette and pictures were taken using a microscope at $40 \times$ magnification after 0 hour, 6 hours and 12 hours. (D) The migration pictures of si-NC and si-495 groups was analyzed. (E) A scratch was performed
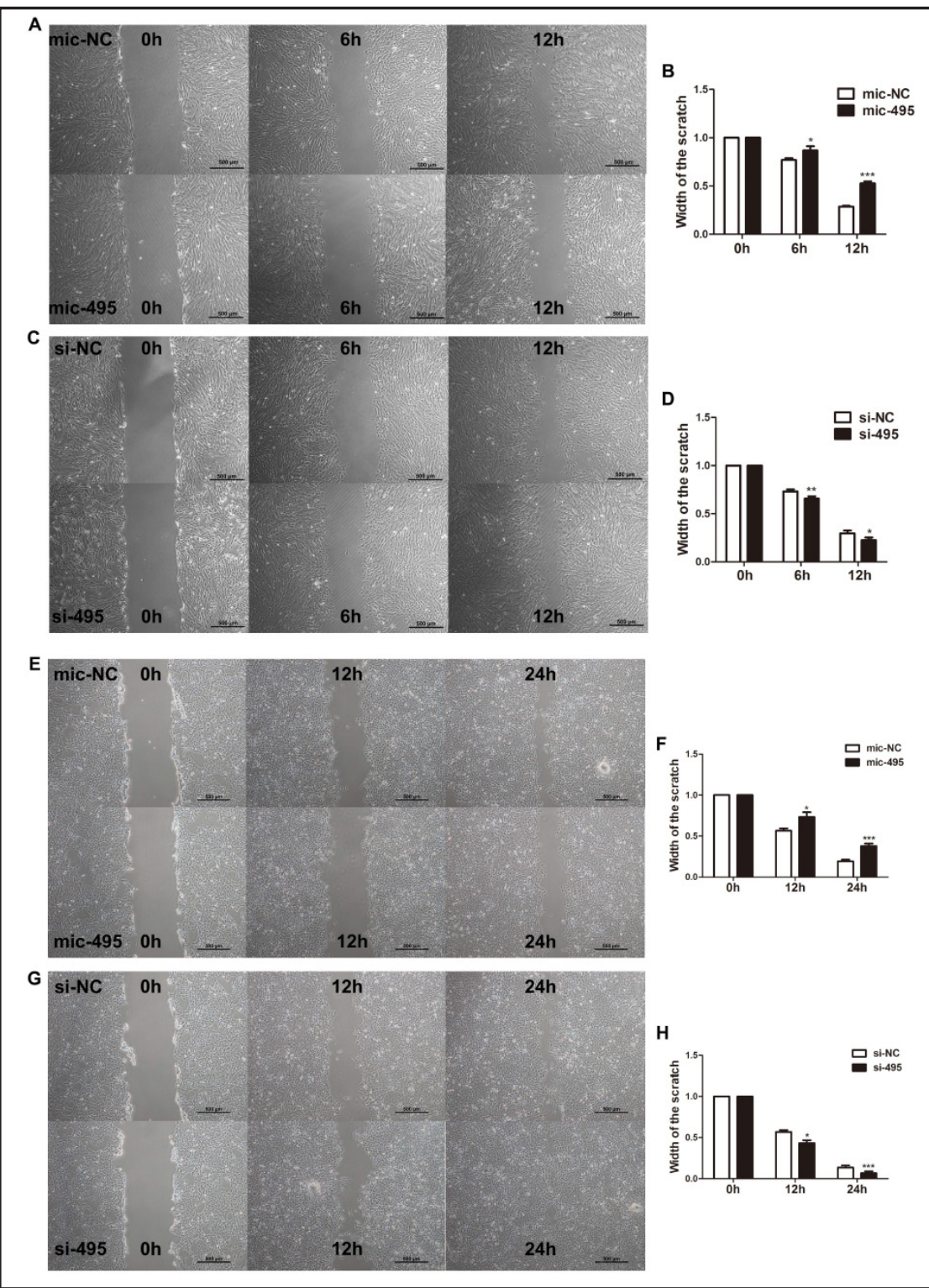

using a $1 \mathrm{ml}$ pipette and then HTR-8/SVneo cells was co-cultured with supernatants of MSCs overexpressed miR-495 and pictures were taken using a microscope at 40× magnification after 0 hour, 12 hours and 24 hours. (F) The migration pictures of si-NC and si-495 groups was analyzed. (G) A scratch was performed using a $1 \mathrm{ml}$ pipette and then HTR-8/SVneo cells was co-cultured with supernatants of MSCs downregulating-miR-495 and pictures were taken using a microscope at 40× magnification after 0 hour, 12 hours and 24 hours. (H) The migration pictures of si-NC and si-495 groups was analyzed. All results are from three independent experiments. Values are means \pm S.E.M. ${ }^{*} \mathrm{P}<0.05,{ }^{* *} \mathrm{P}<0.01,{ }^{* * *} \mathrm{P}<0.001$.

tubes was pictured and analyzed. The results showed that the supernatants of miR-49overexpressed MSCs could inhibit HUVEC capillary formation and downregulated-miR-495 could promote tube formation (Fig. 5E). The relative tubes length of tube-like capillary (\% control) was $1.000 \pm 0.05614$ in mic-NC group and $0.7485 \pm 0.08279$ in miR-495 group (P $=0.0107$ ) (Fig. 5F), $1.000+0.09101$ in si-NC group and $1.524 \pm 0.1145$ in si-495 group $(\mathrm{P}=$ $0.0014)$.

\section{KARGER}


Fig. 5. Supernatants from miR-495-overexpressed-MSCs inhibited the invasion of HTR- $8 / \mathrm{SV}$ neo and tube formation of HUVEC. (A) Analysis of migrated HTR-8/ SVneo cells treated with supernatants from miR-495-overexpressed-MSCs. The number of migrated cells was quantified using a microscope at $100 \times$ magnification after 24 hours. A statistical analysis of the migration experiments was shown on B. (C) Analysis of migrated HTR-8/SVneo cells treated with supernatants from miR-495-downregulated-MSCs. The number of migrated cells was quantified using a microscope at $100 \times$ magnification after 24 hours. A statistical analysis of the migration experiments was shown on D. (E) HUVEC was treated with supernatant from MSCs transfected with mic-495, mic-NC, si-NC and si-495. The tubes were photogra-

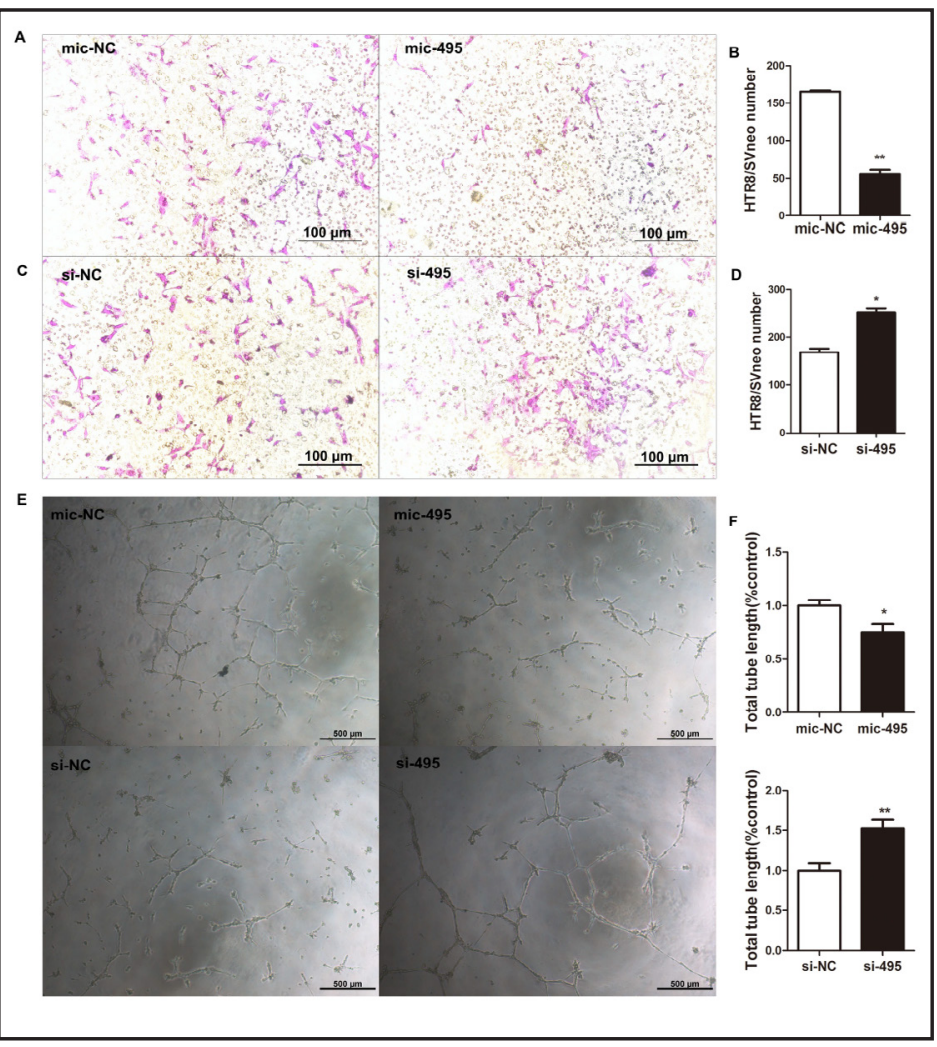
phed under a microscope at $40 \times$ magnification after 8 hours. (F) A statistical analysis of tube formation was shown. All results are from three independent experiments. Values are means \pm S.E.M. ${ }^{*} \mathrm{P}<0.05,{ }^{* *} \mathrm{P}<0.01$, *** $\mathrm{P}<0.001$.

\section{MiR-495 promotes cell senescence}

Normal MSCs in fetal-maternal interface play important roles in achieving successful pregnancies. We wonder whether miR-495 could affect the survival of MSCs. After changing the expression of miR- 495 for 48 hours, we tested the activity of senile related $\beta$-galactosidase using a Senescence $\beta$-galactosidase Staining Kit. The results showed that miR-495overexpressed MSCs showed more blue-staining whereas the miR-495-downregulated MSCs showed little $\beta$-galactosidase staining (Fig. 6A and 6B) compared with negative controls, indicating that miR-495 could promote the senescence of MSCs.

Previous studies reported that CD146 was lowly expressed in senescent MSCs [33, 34], so we tested the expression of CD146 on MSCs surface after transfecting mic-NC or mic- 495 for 48 hours using FACs Calibur both in passage 3 and passage 6 . The results showed that MSCs overexpressing miR-495 expressed less CD146 compared with mic-NC (Fig. 6C and 6D).

Besides, P16, P53 and P21 were reported closely related with cell senescence [35, 36]. So we tested the expression of P16, P53 and P21 after changing the expression of miR-495. The results showed that P16, P53 and P21 were increased in miR-495-overexpressed MSCs (Fig. 6E-6G).

\section{Bmi-1 mediates the effects of miR-495 on MSCs}

Bmi-1 was reported one of the genes inhibit cell senescence $[37,38]$ and inhibiting the expression of Bmi-1 could promote cell senescence [39]. Besides, Bmi-1 was a putative target of miR-495 and, so we wondered whether miR-495 correlated with Bmi- 1 in MSCs. Then we tested the expression of Bmi-1 and the results showed that Bmi-1 was lowly expressed in umbilical cords derived from PE compared with NC (Fig. 7A). Although there was no significance between NC and PE in MSCs, there was a trend that Bmi-1 was lowly expressed 
A
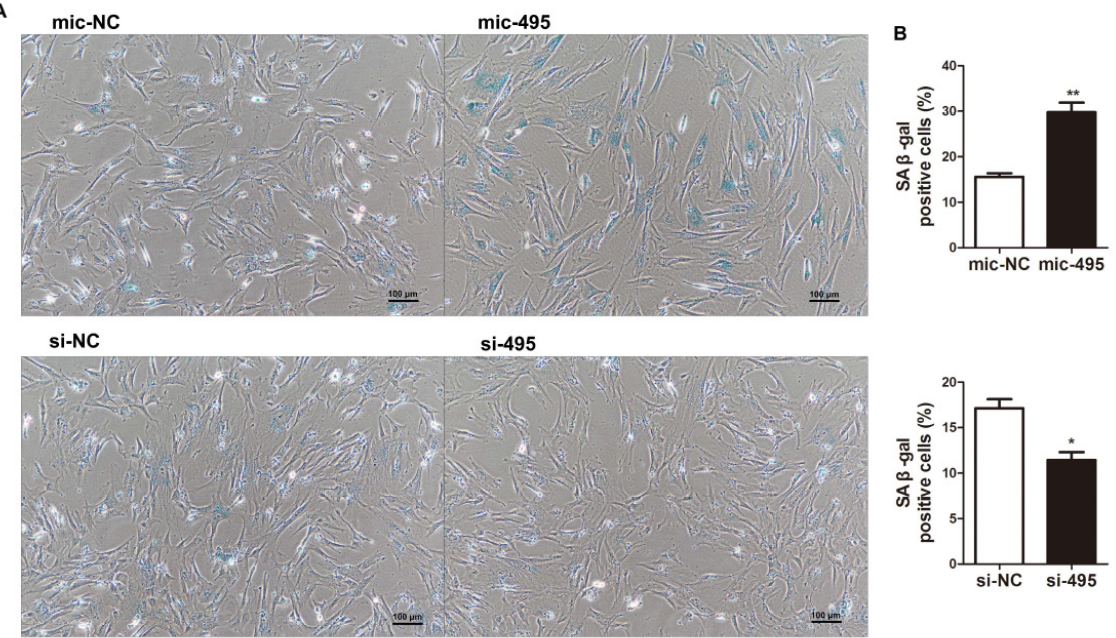

C
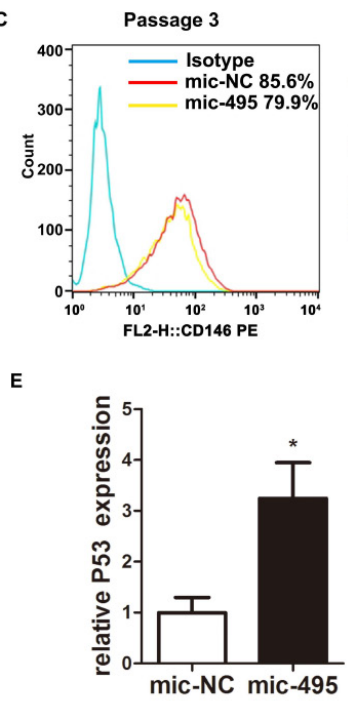

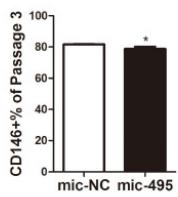

D
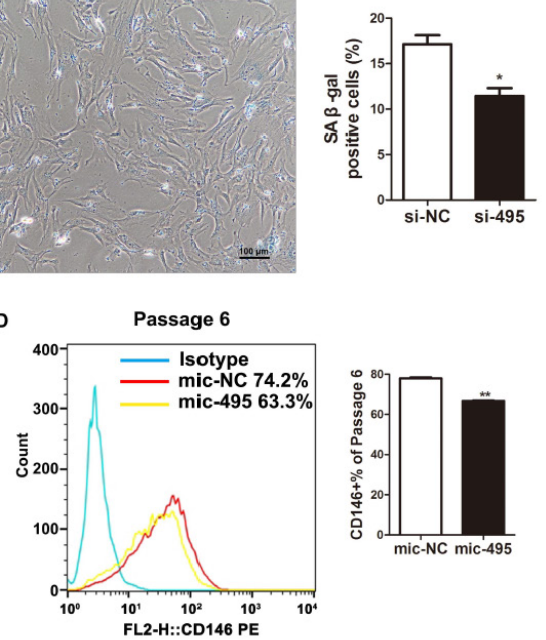

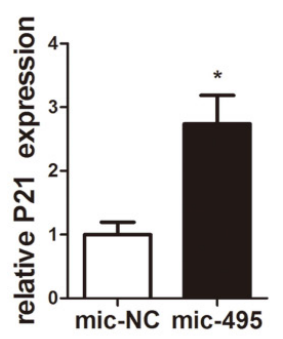

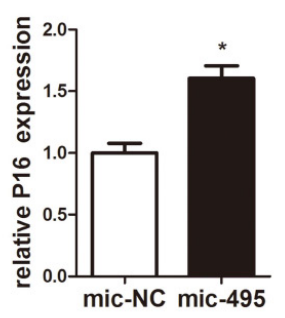

Fig. 6. MiR-495 could promote cell senescence. (A) $\beta$-galactosidase activity was tested after changing the expression of miR-495 in MSCs. After staining for 24 hours, pictures were taken under a microscope at 40× magnification and quantitation was achieved by determining the percentage of SA b-gal-positive cells (B). (C) CD146 expression on the surface of MSCs was tested after overexpressing miR-495 using passage 3 MSCs. (D) CD146 expression on the surface of MSCs was tested after overexpressing miR-495 using passage 6 MSCs. (E) P53 expression was tested after overexpressing miR-495 on mRNA level. (F) P21 expression was tested after overexpressing miR-495 on mRNA level. (G) P16 expression was tested after overexpressing miR-495 on mRNA level. All results are from three independent experiments. Values are means \pm S.E.M. $* \mathrm{P}<0.05,{ }^{* *} \mathrm{P}<0.01,{ }^{* * *} \mathrm{P}<0.001$.

in MSCs derived from PE (Fig. 7B) compared with MSCs derived from NC. Correlation analysis showed there was a linear positive correlation between miR-495 and Bmi-1 $\left(R^{2}=0.1503\right.$, $\mathrm{P}=0.0065$ in umbilical cord tissues and $\mathrm{R}^{2}=0.3511, \mathrm{P}=0.0255$ in MSCs) (Fig. 7C and 7D). Besides, the expression of Bmi-1 was decreased after overexpressing miR-495 in MSCs both at mRNA level (Fig. 7E) and protein level (Fig. 7F). Although there was no significance after silencing miR-495 at mRNA level, there was a trend that Bmi-1 was upregulated by silencing miR-495 at mRNA level (Fig. 7E) and significantly upregulated at protein level (Fig. 7F).

\section{KARGER}




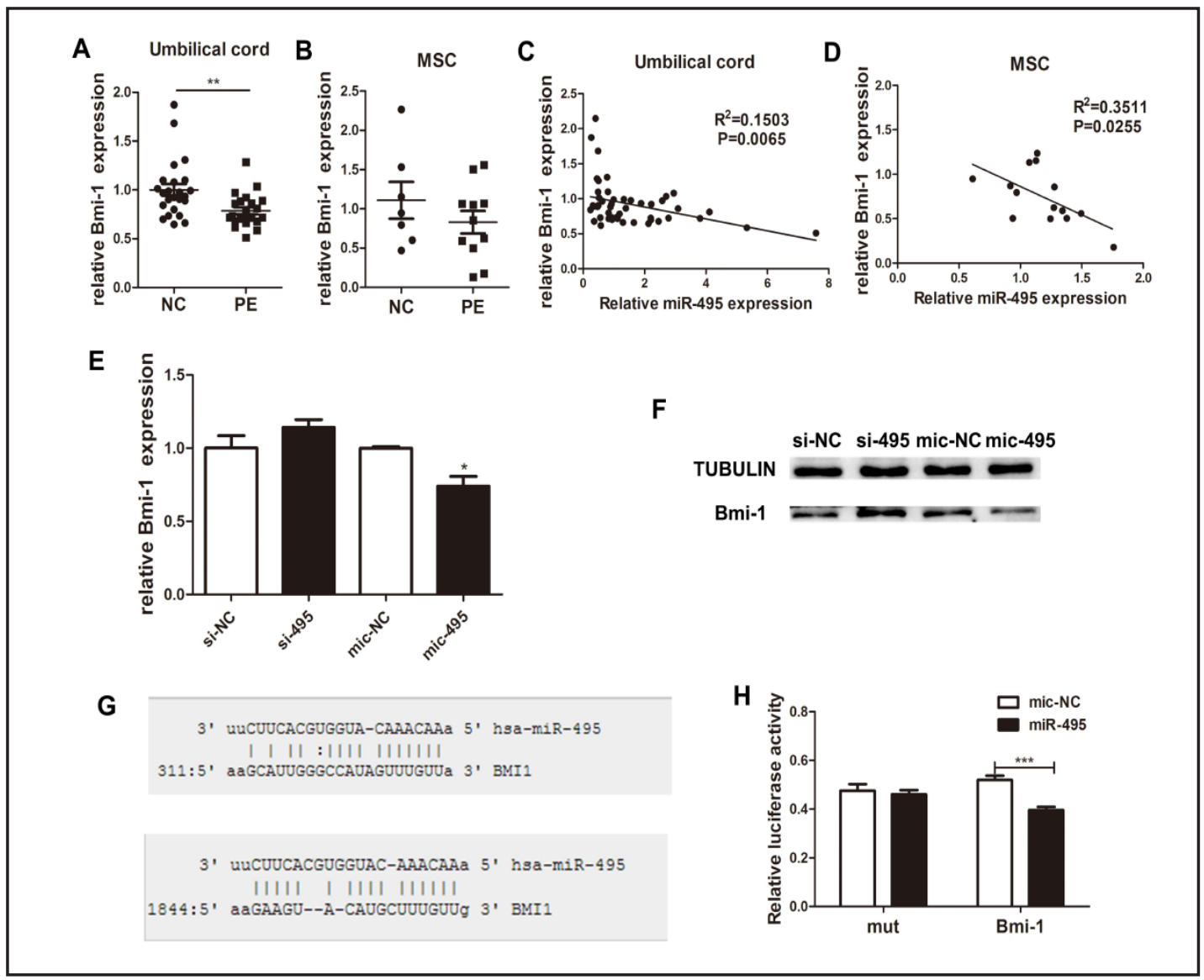

Fig. 7. Bmi-1 was downregulated in the presence of miR-495. (A and B) The relative Bmi-1 expression in umbilical cord tissues and MSCs derived from NC and PE patients. (C and D) There was a negative linear correlation between miR-495 and Bmi- 1 both in umbilical cords $\left(R^{2}=0.1503, P=0.0065\right)$ and MSCs $\left(R^{2}\right.$ $=0.3511, \mathrm{P}=0.0255)$. After 48 hours of transfection with mic-495, mic-NC, si-NC or si-495, total RNAs, protein of MSCs were collected respectively and Q-PCR (E) and western blotting (F) were performed to detect the levels of Bmi-1. (G) There are two regions on Bmi-1 mRNA miR-495 can bind. (H) Analysis of luciferase intensity in cells co-transfected with mic-NC or miR-495 and plasmid containing Bmi-1-mut or the 3'UTR of Bmi-1. All results are from three independent experiments. Values are means \pm S.E.M. $* \mathrm{P}<0.05,{ }^{* *} \mathrm{P}<$ $0.01,{ }^{* * *} \mathrm{P}<0.001$.

There were two regions on the Bmi-1 mRNA miR-495 could bind (Fig. 7G). Then the dual-luciferase assay was performed to confirm the relationship between miR-495 and Bmi-1. As is shown in Fig. $7 \mathrm{H}$, the relative luciferase intensity was significantly decreased in cells co-transfected with miR-495 and reporter plasmid containing the 3' untranslated regions ( $3^{\prime}$ UTR) of Bmi-1 for 48h compared with that co-transfected with miR-495 and plasmid containing Bmi-1-mut and mic-NC group, indicating that miR-495 could inhibit the expression of Bmi-1 through targeting the 3'UTR of Bmi-1.

\section{Discussion}

The umbilical cord is an important source of MSCs. Aberrant levels of cytokines were observed in MSCs from patients with PE and abnormal MSCs are associated with the origin of preeclampsia development [40]. These findings suggest that abnormal MSCs may contribute to PE development. In our previous study, we found that miR-495 was one of 
the highly elevated miRNA in decidua-derived MSCs from PE patients [31]. Therefore, we speculated that miR-495 in MSCs may be involved in the pathogenesis of PE. In the present study, we found that overexpressed miR-495 inhibited cell proliferation, migration, invasion and angiogenesis. Besides, overexpressed miR-495 could also promote cell apoptosis and senescence through decreasing the production of Bmi-1. These findings suggest that miR495 may be involved in the pathogenesis of PE.

Cellular senescence was reported to be triggered by the gradual accumulation of DNA damage and epigenetic alterations that can directly affect the expression of senescenceassociated genes [41]. Because of incomplete and erratic DNA replication, irreversible changes take place in the nuclei of senescent cells, which can limit the cell division and induce cell senescence [42-44]. Senescence can be induced through activating various signaling pathways, such as P53, NF- $\kappa$ B, PI3K/AKT, ERK/JNK/P38-MAPK [45].

Bmi-1 (B cell-specific Moloney murine leukemia virus integration site 1), a member of the polycomb family of transcriptional repressors, was initially identified as a c-myc cooperating oncogene in the induction of B-cell lymphoma $[46,47]$. In mice, the absence of Bmi-1 expression results in neurological defects and severe proliferative defects in lymphoid cells, whereas Bmi-1 overexpression induces lymphomas [48, 49]. Besides, Bmi-1 was involved in cell cycle regulation, self-renewal of stem cells and cell senescence [50-54] and lacking Bmi-1 could inhibit cell proliferation and promote cell apoptosis [55, 56]. Bmi-1 was also reported to promote invasion and metastasis [57]. Bmi-1 could also promote glioma angiogenesis by activating NF- $\kappa B$ signaling [58]. What's more, UCB-MSCs (umbilical cord blood derived MSCs) exhibited the typical senescent phenotype when knocked down Bmi-1 [59]. In our current study, we found that Bmi-1 was lowly expressed in the umbilical cord tissues and MSCs derived from PE compared with healthy pregnancies while miR-495 was highly expressed. What's more, there was a negative liner-relationship between Bmi-1 and miR-495.

Previous studies have shown that miR-495 was broadly involved in a variety of cancers and it plays critical roles in distinct cancer hallmark capabilities to contribute to cancer, such as non-small cell lung cancer (NSCLC), gastric cancer cells, prostate cancer cells and renal cancer cells $[26,60-63]$ through inhibiting proliferation, migration, invasion, angiogenesis and other ways. MiR-495 was also reported to inhibit chondrogenic differentiation of MSCs [64]. But whether miR-495 could affect the senescence of MSCs was still unknown. In our study, we first demonstrated that miR-495 was an important endogenous regulator in MSCs which could not only affect cell proliferation, migration, invasion and angiogenesis properties, but also inducing cell senescence of MSCs through targeting Bmi-1. Thus, miR495 might be a promising target to cure PE.

Collectively, in our study, we work on the relationship between MSCs and miR-495, attempting to explain how the highly expressed microRNA plays the role in the development of PE. Overexpressed miR-495 inhibits the growth, migration, invasion and promoting cell senescence and apoptosis by decreasing the expression of Bmi-1. The present study reveals that miR-495 arrests cell cycle at S transition and affects MSCs' proliferation, migration and tube formation functions and may be a novel mechanism in the development of PE.

However, there are some defects and limitations in some respects. First, we reported that there were several miRNAs which were highly expressed in PE, and we just investigated the effects of miR-495 on MSCs and did not explore the combined effect of miR-495 with other changed microRNAs, there is need to study furthermore. Secondly, although miR-495 could affect some interesting phenomena, it is still unknown whether miR-495 is of importance to cause the symptom of PE or inhibition of miR-495 can reverse the development of PE symptom in vivo. It needs to be further explored. Thirdly, although the phenomena caused by changing miR-495 can be explained by Bmi-1, whether there are other targets miR-495 plays roles through is still unknown. Besides, after senescence induced by miR-495, what factors changed in the supernatants inhibits the migration, invasion etc. is also needs to be further investigated.

\section{KARGER}




\begin{tabular}{|c|c|c|}
\hline Cellular & Cell Physiol Biochem 2017 & 12:780-796 \\
\hline and Biochemistry & $\begin{array}{l}\text { DOI: } 10.1159 / 000478069 \\
\text { Publisned online: June 19, } 2017\end{array}$ & $\begin{array}{l}\text { (O) } 2017 \text { The Author(s). Published by S. Karger AG, Basel } \\
\text { www.karger.com/cpb }\end{array}$ \\
\hline
\end{tabular}

\section{Conclusion}

In conclusion, our findings suggest that miR-495 was highly expressed in PE and thus it can attenuates the proliferation, invasion, migration, tube formation ability of MSCs and promote MSCs apoptosis and senescence through downregulating Bmi-1. Therefore, miR495 may be a potential target for PE treatment.

\section{Acknowledgments}

This work was supported by the National Natural Science Foundation of China (81401223), Jiangsu Provincial Key Medical Talent (RC201670) and Six Talent Peaks Project in Jiangsu Province (2016-WSW-063).

We thank NovelBio Ltd., Co for the support of bioinformatics analysis with their NovelBrain Cloud Platform (www.novelbrain.com).

\section{Disclosure Statement}

The authors indicate no potential conflicts of interest.

\section{References}

Sibai B, Dekker G, Kupferminc M: Pre-eclampsia. The Lancet 2005;365:785-799.

Redman CW, Sargent IL: Latest advances in understanding preeclampsia. Science 2005;308:1592-1594.

Jia R, Li J, Rui C, Ji H, Ding H, Lu Y, De W, Sun L: Comparative proteomic profile of the human umbilical cord blood exosomes between normal and preeclampsia pregnancies with high-resolution mass spectrometry. Cell Physiol Biochem 2015;36:2299-2306.

-4 Li H, Han L, Yang Z, Huang W, Zhang X, Gu Y, Li Y, Liu X, Zhou L, Hu J, Yu M, Yang J, Li Y, Zheng Y, Guo J, Han J, Li L: Differential proteomic analysis of syncytiotrophoblast extracellular vesicles from early-onset severe preeclampsia, using 8-plex itraq labeling coupled with 2d nano lc-ms/ms. Cell Physiol Biochem 2015;36:1116-1130.

5 Li J, Ying H, Cai G, Guo Q, Chen L: Pre-eclampsia-associated reduction in placental growth factor impaired beta cell proliferation through pi3k signalling. Cell Physiol Biochem 2015;36:34-43.

6 McElreavey KD, Irvine AI, Ennis KT, McLean WH: Isolation, culture and characterisation of fibroblast-like cells derived from the wharton's jelly portion of human umbilical cord. Biochem Soc T 1991;19:29s.

7 Chen A, Li C, Wang J, Sha H, Piao S, Liu S: Role of toll-like receptor 3 gene polymorphisms in preeclampsia. Cell Physiol Biochem 2015;37:1927-1933.

8 Nuzzo AM, Giuffrida D, Masturzo B, Mele P, Piccoli E, Eva C, Todros T, Rolfo A: Altered expression of g1/s phase cell cycle regulators in placental mesenchymal stromal cells derived from preeclamptic pregnancies with fetal-placental compromise. Cell Cycle 2017;16:200-212.

-9 Liu L, Zhao G, Fan H, Zhao X, Li P, Wang Z, Hu Y, Hou Y: Mesenchymal stem cells ameliorate th1-induced preeclampsia-like symptoms in mice via the suppression of tnf-alpha expression. PloS One 2014;9:e88036.

10 Fu L, Liu Y, Zhang D, Xie J, Guan H, Shang T: Beneficial effect of human umbilical cord-derived mesenchymal stem cells on an endotoxin-induced rat model of preeclampsia. Exp Ther Med 2015;10:1851-1856.

11 Li X, Song Y, Liu F, Liu D, Miao H, Ren J, Xu J, Ding L, Hu Y, Wang Z, Hou Y, Zhao G: Long non-coding rna malat1 promotes proliferation, angiogenesis and immunosuppressive properties of mesenchymal stem cells by inducing vegf and ido. J Cell Biochem DOI: 10.1002/jcb.25927.

12 Wang Y, Fan H, Zhao G, Liu D, Du L, Wang Z, Hu Y, Hou Y: Mir-16 inhibits the proliferation and angiogenesisregulating potential of mesenchymal stem cells in severe pre-eclampsia. FEBS J 2012;279:4510-4524.

13 Hu E, Ding L, Miao H, Liu F, Liu D, Dou H, Hou Y: Mir-30a attenuates immunosuppressive functions of il1beta-elicited mesenchymal stem cells via targeting tab3. FEBS lett 2015;589:3899-3907. 


\section{Cellular Physiology Cell Physiol Biochem 2017;42:780-796

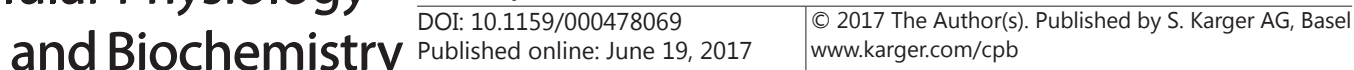

14 Liu L, Wang Y, Fan H, Zhao X, Liu D, Hu Y, Kidd AR, 3rd, Bao J, Hou Y: Microrna-181a regulates local immune balance by inhibiting proliferation and immunosuppressive properties of mesenchymal stem cells. Stem Cells 2012;30:1756-1770.

15 Zhao G, Miao H, Li X, Chen S, Hu Y, Wang Z, Hou Y: Tgf-beta3-induced mir-494 inhibits macrophage polarization via suppressing pge2 secretion in mesenchymal stem cells. FEBS lett 2016;590:1602-1613.

16 Cox LS, Redman C: The role of cellular senescence in ageing of the placenta. Placenta DOI:10.1016/j.

17 Mayne BT, Leemaqz SY, Smith AK, Breen J, Roberts CT, Bianco-Miotto T: Accelerated placental aging in early onset preeclampsia pregnancies identified by DNA methylation. Epigenomics 2017;9:279-289.

-18 Sukenik-Halevy R, Amiel A, Kidron D, Liberman M, Ganor-Paz Y, Biron-Shental T: Telomere homeostasis in trophoblasts and in cord blood cells from pregnancies complicated with preeclampsia. Am J Obstet Gynecol 2016;214:283 e281-287.

19 Li M, Zhao Y, Hao H, Dong L, Liu J, Han W, Fu X: Umbilical cord-derived mesenchymal stromal cellconditioned medium exerts in vitro antiaging effects in human fibroblasts. Cytotherapy 2017;19:371-383.

20 Rodrigues CE, Capcha JM, de Braganca AC, Sanches TR, Gouveia PQ de Oliveira PA, Malheiros DM, Volpini RA, Santinho MA, Santana BA, Calado RD, Noronha IL, Andrade L: Human umbilical cord-derived mesenchymal stromal cells protect against premature renal senescence resulting from oxidative stress in rats with acute kidney injury. Stem Cell Res Ther 2017;8:19.

21 Banfi A, Muraglia A, Dozin B, Mastrogiacomo M, Cancedda R, Quarto R: Proliferation kinetics and differentiation potential of ex vivo expanded human bone marrow stromal cells: Implications for their use in cell therapy. Exp Hematol 2000;28:707-715.

22 Baxter MA, Wynn RF, Jowitt SN, Wraith JE, Fairbairn LJ, Bellantuono I: Study of telomere length reveals rapid aging of human marrow stromal cells following in vitro expansion. Stem Cells 2004;22:675-682.

-23 Yoo JK, Kim CH, Jung HY, Lee DR, Kim JK: Discovery and characterization of mirna during cellular senescence in bone marrow-derived human mesenchymal stem cells. Exp gerontol 2014;58:139-145.

-24 Candini O, Spano C, Murgia A, Grisendi G, Veronesi E, Piccinno MS, Ferracin M, Negrini M, Giacobbi F, Bambi F, Horwitz EM, Conte P, Paolucci P, Dominici M: Mesenchymal progenitors aging highlights a mir-196 switch targeting hoxb7 as master regulator of proliferation and osteogenesis. Stem Cells 2015;33:939-950.

25 Qian Y, Lu Y, Rui C, Qian Y, Cai M, Jia R: Potential significance of circular rna in human placental tissue for patients with preeclampsia. Cell Physiol Biochem 2016;39:1380-1390.

-26 Lv C, Bai Z, Liu Z, Luo P, Zhang J: Microrna-495 suppresses human renal cell carcinoma malignancy by targeting satb1. Am J Transl Res 2015;7:1992-1999.

27 Mao Y, Li L, Liu J, Wang L, Zhou Y: Mir-495 inhibits esophageal squamous cell carcinoma progression by targeting akt1. Oncotarget DOI:10.18632/oncotarget.9981.

-28 Xu YY, Tian J, Hao Q Yin LR: Microrna-495 downregulates foxc1 expression to suppress cell growth and migration in endometrial cancer. Tumour Biol. 2016;37:239-251.

-29 Chen SM, Chen HC, Chen SJ, Huang CY, Chen PY, Wu TW, Feng LY, Tsai HC, Lui TN, Hsueh C, Wei KC: Microrna-495 inhibits proliferation of glioblastoma multiforme cells by downregulating cyclin-dependent kinase 6. World J Surg Oncol 2013;11:87.

-30 Wang L, Liu JL, Yu L, Liu XX, Wu HM, Lei FY, Wu S, Wang X: Downregulated mir-495 [corrected] inhibits the g1-s phase transition by targeting bmi-1 in breast cancer. Medicine 2015;94:e718.

-31 Zhao G, Zhou X, Chen S, Miao H, Fan H, Wang Z, Hu Y, Hou Y: Differential expression of micrornas in decidua-derived mesenchymal stem cells from patients with pre-eclampsia. J Biomed Sci 2014;21:81.

-32 Dominici M, Le Blanc K, Mueller I, Slaper-Cortenbach I, Marini F, Krause D, Deans R, Keating A, Prockop D, Horwitz E: Minimal criteria for defining multipotent mesenchymal stromal cells. The international society for cellular therapy position statement. Cytotherapy 2006;8:315-317.

-33 Gurung S, Werkmeister JA, Gargett CE: Inhibition of transforming growth factor-beta receptor signaling promotes culture expansion of undifferentiated human endometrial mesenchymal stem/stromal cells. Sci Rep 2015;5:15042.

34 Jin HJ, Kwon JH, Kim M, Bae YK, Choi SJ, Oh W, Yang YS, Jeon HB: Downregulation of melanoma cell adhesion molecule (mcam/cd146) accelerates cellular senescence in human umbilical cord blood-derived mesenchymal stem cells. Stem Cell Transl Med 2016;5:427-439.

-35 Cheng Z, Zheng YZ, Li YQ Wong CS: Cellular senescence in mouse hippocampus after irradiation and the role of p53 and p21. J Neuropath Exp Neu D0I:10.1093/jnen/nlx006. 


\section{Cellular Physiology Cell Physiol Biochem 2017;42:780-796 \begin{tabular}{l|l} 
DOI: 10.1159/000478069 & $\begin{array}{l}\text { O 2017 The Author(s). Published by S. Karger AG, Basel } \\
\text { www.karger.com/cpb }\end{array}$ \\
\hline
\end{tabular}}

Li et al.: MiR-495 Contributes to the Pathogenesis of PE

-36 Lin HK, Chen Z, Wang G, Nardella C, Lee SW, Chan CH, Yang WL, Wang J, Egia A, Nakayama KI, CordonCardo C, Teruya-Feldstein J, Pandolfi PP: Skp2 targeting suppresses tumorigenesis by arf-p53-independent cellular senescence. Nature 2010;464:374-379.

-37 Lukacs RU, Memarzadeh S, Wu H, Witte ON: Bmi-1 is a crucial regulator of prostate stem cell self-renewal and malignant transformation. Cell Stem Cell 2010;7:682-693.

-38 Park IK, Qian D, Kiel M, Becker MW, Pihalja M, Weissman IL, Morrison SJ, Clarke MF: Bmi-1 is required for maintenance of adult self-renewing haematopoietic stem cells. Nature 2003;423:302-305.

-39 Gao FL, Li WS, Liu CL, Zhao GQ: Silencing bmi-1 enhances the senescence and decreases the metastasis of human gastric cancer cells. World J Gastroente 2013;19:8764-8769.

-40 Hwang JH, Lee MJ, Seok OS, Paek YC, Cho GJ, Seol HJ, Lee JK, Oh MJ: Cytokine expression in placenta-derived mesenchymal stem cells in patients with pre-eclampsia and normal pregnancies. Cytokine 2010;49:95101.

41 Shin DM, Kucia M, Ratajczak MZ: Nuclear and chromatin reorganization during cell senescence and aging a mini-review. Gerontology 2011;57:76-84.

42 Blasco MA: Telomeres and human disease: Ageing, cancer and beyond. Nat Rev Genet 2005;6:611-622.

43 Hayflick L: The limited in vitro lifetime of human diploid cell strains. Exp Cell Res 1965;37:614-636.

44 Oberdoerffer P, Sinclair DA: The role of nuclear architecture in genomic instability and ageing. Nat Rev Mol Cell bio 2007;8:692-702.

45 Finkel T, Holbrook NJ: Oxidants, oxidative stress and the biology of ageing. Nature 2000;408:239-247.

-46 van Lohuizen M, Verbeek S, Scheijen B, Wientjens E, van der Gulden H, Berns A: Identification of cooperating oncogenes in e mu-myc transgenic mice by provirus tagging. Cell 1991;65:737-752.

47 Haupt Y, Alexander WS, Barri G, Klinken SP, Adams JM: Novel zinc finger gene implicated as myc collaborator by retrovirally accelerated lymphomagenesis in e mu-myc transgenic mice. Cell 1991;65:753763.

-48 van der Lugt NM, Domen J, Linders K, van Roon M, Robanus-Maandag E, te Riele H, van der Valk M, Deschamps J, Sofroniew M, van Lohuizen M, et al.: Posterior transformation, neurological abnormalities, and severe hematopoietic defects in mice with a targeted deletion of the bmi-1 proto-oncogene. Gene Dev 1994;8:757-769.

49 Alkema MJ, Jacobs H, van Lohuizen M, Berns A: Pertubation of b and t cell development and predisposition to lymphomagenesis in emu bmi1 transgenic mice require the bmi1 ring finger. Oncogene 1997;15:899910.

50 Wang Y, Guan Y, Wang F, Huang A, Wang S, Zhang YA: Bmi-1 regulates self-renewal, proliferation and senescence of human fetal neural stem cells in vitro. Neurosci Lett 2010;476:74-78.

51 Lv X, Yu Z, Xie C, Dai X, Li Q, Miao D, Jin J: Bmi-1 plays a critical role in the protection from acute tubular necrosis by mobilizing renal stem/progenitor cells. Biochem Bioph Res Co 2016

-52 Zhang HW, Ding J, Jin JL, Guo J, Liu JN, Karaplis A, Goltzman D, Miao D: Defects in mesenchymal stem cell self-renewal and cell fate determination lead to an osteopenic phenotype in bmi-1 null mice. J Bone Miner Res 2010;25:640-652.

53 Jacobs JJ, Kieboom K, Marino S, DePinho RA, van Lohuizen M: The oncogene and polycomb-group gene bmi-1 regulates cell proliferation and senescence through the ink4a locus. Nature 1999;397:164-168.

54 Lessard J, Sauvageau G: Bmi-1 determines the proliferative capacity of normal and leukaemic stem cells. Nature 2003;423:255-260.

-55 Jacobs JJ, Scheijen B, Voncken JW, Kieboom K, Berns A, van Lohuizen M: Bmi-1 collaborates with c-myc in tumorigenesis by inhibiting c-myc-induced apoptosis via ink4a/arf. Gene Dev 1999;13:2678-2690.

56 He X, Dong Y, Wu CW, Zhao Z, Ng SS, Chan FK, Sung JJ, Yu J: Microrna-218 inhibits cell cycle progression and promotes apoptosis in colon cancer by downregulating bmi1 polycomb ring finger oncogene. Mol Med 2013;18:1491-1498.

57 Guo BH, Feng Y, Zhang R, Xu LH, Li MZ, Kung HF, Song LB, Zeng MS: Bmi-1 promotes invasion and metastasis, and its elevated expression is correlated with an advanced stage of breast cancer. Mol Cancer 2011;10:10.

58 Jiang L, Song L, Wu J, Yang Y, Zhu X, Hu B, Cheng SY, Li M: Bmi-1 promotes glioma angiogenesis by activating nf-kappab signaling. PloS One 2013;8:e55527. 


\section{Cellular Physiology Cell Physiol Biochem 2017;42:780-796 \begin{tabular}{l|l} 
DOI: 10.1159/000478069 & a 2017 The Author(s). Published by S. Karger AG, Basel \\
www.karger.com/cpb
\end{tabular} \\ Li et al.: MiR-495 Contributes to the Pathogenesis of PE}

-59 Jin HJ, Lee HJ, Heo J, Lim J, Kim M, Kim MK, Nam HY, Hong GH, Cho YS, Choi SJ, Kim IG, Shin DM, Kim SW: Senescence-associated mcp-1 secretion is dependent on a decline in bmi1 in human mesenchymal stromal cells. Antioxid Redox Sign 2016;24:471-485.

60 Chu H, Chen X, Wang H, Du Y, Wang Y, Zang W, Li P, Li J, Chang J, Zhao G, Zhang G: Mir-495 regulates proliferation and migration in nsclc by targeting mta3. Tumour Bio 2014;35:3487-3494.

61 Lee SH, Jung YD, Choi YS, Lee YM: Targeting of runx3 by mir-130a and mir-495 cooperatively increases cell proliferation and tumor angiogenesis in gastric cancer cells. Oncotarget 2015;6:33269-33278.

-62 Luizon MR, Palei AC, Belo VA, Amaral LM, Lacchini R, Duarte G, Cavalli RC, Sandrim VC, Tanus-Santos JE: Gene-gene interactions in the nampt pathway, plasma visfatin/nampt levels, and antihypertensive therapy responsiveness in hypertensive disorders of pregnancy. Pharmacogenomics J DOI:10.1038/tpj.2016.35.

63 Liang J, Huang W, Cai W, Wang L, Guo L, Paul C, Yu XY, Wang Y: Inhibition of microrna-495 enhances therapeutic angiogenesis of human induced pluripotent stem cells. Stem cells DOI:10.1002/stem.2477.

64 Lee S, Yoon DS, Paik S, Lee KM, Jang Y, Lee JW: Microrna-495 inhibits chondrogenic differentiation in human mesenchymal stem cells by targeting sox9. Stem Cells Dev 2014;23:1798-1808. 